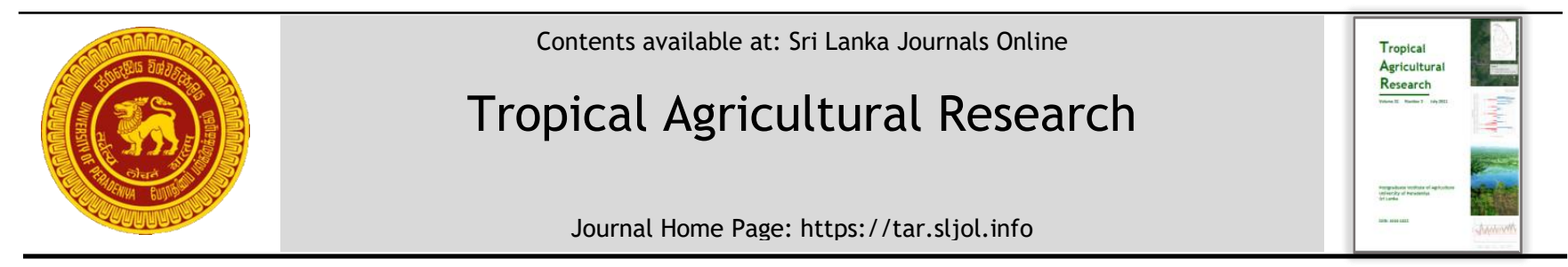

\title{
Functional Impairment of Bovine Spermatozoa by Fungicide Mancozeb: an in vitro Exposure Study
}

C. Kodithuwakku', Y.G.M. Prasadani ${ }^{1}$, M.P.B. Wijayagunawardhane ${ }^{1}$, C. Rathnayake ${ }^{1}$, K.F. Lee ${ }^{3}$ and S.P. Kodithuwakku1,3*

${ }_{1}^{1}$ Department of Animal Science, Faculty of Agriculture, University of Peradeniya, Peradeniya, Sri Lanka.

2 Department of Obstetrics and Gynaecology, Faculty of Medicine, University of Peradeniya, Peradeniya, Sri Lanka

${ }^{3}$ Department of Obstetrics and Gynaecology, LKS Faculty of Medicine, University of Hong Kong, Hong Kong SAR, PRC

\section{ARTICLE INFO}

\section{Article history:}

Received: 7 August 2020

Revised version received: 15 December 2020

Accepted: 22 December 2021

Available online: 30 July 2021

\section{Keywords:}

Acrosome functions,

bovine spermatozoa,

computer assisted sperm analysis,

Mancozeb,

sperm motility

\section{Citation:}

Kodithuwakku, C., Prasadani, Y.G.M.

Wijayagunawardhane, M.P.B.,

Rathnayake, C., Lee, K.F. and

Kodithuwakku S.P. (2021). Functional

impairment of bovine spermatozoa by

fungicide Mancozeb: An in vitro exposure

study. Tropical Agricultural Research,

32(3): 368-379.

DOI: http://doi.org/10.4038/tar.v32i3.8500

Kodithuwakku, C.

https://orcid.org/0000 000258041433

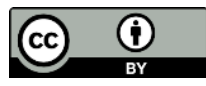

\section{ABSTRACT}

Agrochemicals have been identified as endocrine disruptors affecting many bodily functions of animals, especially the fertility of males. Evidence of various agrochemicals affecting male reproductive functions are plenty. However, evidence on disruptive effects of fungicides on sperm functions is scarce. Therefore, an in vitro study was conducted to investigate acute effects of the fungicide Mancozeb on spermatozoa functions using a bovine spermatozoa model. Semen samples were obtained from fertility proven Jersey bulls and were exposed to series of Mancozeb concentrations $(0.01 \mu \mathrm{g} / \mathrm{ml}$ to $10 \mu \mathrm{g} / \mathrm{ml})$, and the changes occurred in sperm motility parameters, acrosine proteolytic activity and acrosome integrity were assessed at different time intervals. Pure and commercial forms of Mancozeb were in the study, and sperm motility parameters were measured using computer assisted sperm analysis (CASA). Mancozeb concentration of $1 \mu \mathrm{g} / \mathrm{ml}$ with 2 hours exposure significantly $(p \leq 0.05)$ reduced the total sperm motility and the sperm progressive motility. Velocity parameters like average path, straight line, curvy linear and amplitude lateral head displacement were significantly $(\mathrm{p} \leq 0.05)$ reduced after 2 hours in both pure and commercial Mancozeb treatments of $1 \mu \mathrm{g} / \mathrm{ml}$. However, the beat cross frequency and elongation of the sperm were significantly $(\mathrm{p} \leq 0.05)$ reduced only with commercial Mancozeb. Further, the acrosome integrity and proteolytic activity of the acrosome enzymes were significantly $(p \leq 0.05)$ compromised by both Mancozeb treatments. The study revealed that Mancozeb ( $>1 \mathrm{ug} / \mathrm{ml}$ ) could reduce the sperm motility and impairment of acrosome activity significantly. Nevertheless, commercial Mancozeb formulation has the highest impact on the sperm functions. Thus, Mancozeb may affect the fertilization capacity of the spermatozoa under acute exposure

*Corresponding author: surangap@pdn.ac.lk 


\section{INTRODUCTION}

During the last six decades both male and female fertility has shown a decreasing trend in humans as well as in farm animals all over the world (Liu and Ding, 2017; Mendonca et al., 2017; Sifakis et al., 2017; Crowe et al., 2018; Melodie and Christine, 2018). The current level of infertility among humans has doubled the level compared to the last fifty years (Olsen et al., 2011; Yoldemir and Oral, 2012; Mendonca et al., 2017; Melodie and Christine, 2018). Since 1973, the average sperm count among adult males has been reducing at an annual declining rate of 2\% (Adewoyin et al., 2017; De Angelis et al., 2017). Many agro-chemical compounds have now been identified as having disruptive effects on various physiological and endocrine functions of germ cells, and hence, been classified as endocrine disruptive chemicals (EDCs; Sweeney et al., 2015).

Endocrine disruptive chemicals can be synthetic or naturally occurring compounds which mimic hormonal actions by interacting with hormone receptors in the cells. Hence, EDCs can lead to many adversities due to the impact on deregulation of the endocrine system (Albrecht et al., 2016; Skinner, 2016). Humans, farm animals and wildlife are now being continuously exposed to different doses of pesticides via water, food and the environment (Giulivo et al., 2016; Nicolopoulou-Stamati et al., 2016; Sifakis et al., 2017). Many of these agrochemicals have endocrine disruptive properties, and as a result, some of them have been banned from use in agriculture (Ewence et al.,2015). Evidence suggest that many endocrine disrupters could affect both the male and female reproductive systems, and a majority of the fungicides, insecticides and herbicides that are found in the agricultural environments have been classified as EDCs. With the increasing food production and the use of agrochemicals that go tandem with it, the fertility status of humans and animals has shown a decline (Runkle et al., 2017). Although in many cases the etiology of subfertility or infertility is classified as idiopathic or unexplained, the male subfertility/infertility problem is found to be not only genetic, but also due to occupational and environmental factors (Tournaye et al., 2016). In fact, there are increasing evidence to suggest that pesticides can function as endocrine disruptors and alter semen quality and quantity even with continuous exposure to low concentrations (Chiu et al., 2015; Den Hond et al., 2015; Sweeney et al., 2015; Niederberger, 2016).

Mancozeb (ethylene-bis-dithiocarbamate manganese-zinc) is a widely used fungicide, which belongs to the dithiocarbamate family of pesticides and is identified as a potential endocrine disruptor (Sengupta and Banerjee, 2014; Runkle et al., 2017). Many studies have confirmed reproductive and developmental toxicities of Mancozeb in mammals including humans, suggesting that males chronically exposed to mancozeb have significantly altered biochemical, physiological and pathological processes in their bodies leading to infertility (Runkle et al., 2017). The dermal exposure of Mancozeb in farm workers has been empirically determined to be at $3.6 \pm 2.5 \mathrm{mg} / \mathrm{d}$ (Lesmes-Fabian and Binder, 2013) in Colombia; 0.5 - $3.4 \mu \mathrm{g}$ ETU/g creatinine (Colosio et al., 2002), and up to $95.3 \mu \mathrm{g}$ ETU/g creatinine (Colosio et al., 2006) in Italy. However, no such studies have been conducted in Asian countries including Sri Lanka, where Mancozeb is the third highly used pesticide in the area. Although the disruptive effects of Mancozeb in the female reproductive functions are already been documented (Rossi et al., 2006a; Cecconi et al., 2007; Kjeldsen et al., 2013), there are only limited studies conducted on its effects on the male reproductive functions (Rossi et al., 2006b). Mancozeb induces gonadal toxicity, alters the oestrous cycle in female Wistar rats (Baligar and Kaliwal, 2001; Iorio et al., 2014), and impairs the spindle formation and development of oocytes and embryos (Szabo et al., 2003; Rossi et al., 2006a). Furthermore, ovarian granulosa cells which were exposed to Mancozeb has shown pre-malignant like morphology with reported changes in p53 gene expression (Paro et al., 2012). Further, it was reported that the mitochondrial activity, redox status and ATO production have also been affected by the Mancozeb in granulosa cells (Iorio et al., 2015). The Genotoxic effect of Mancozeb was reported in rat models where Mancozeb induced DNA damage (Goldoni et al., 2014) and reduced cell viability (Hoffman and Hardej, 2012) have been revealed. Interestingly, Mancozeb is one of the pesticides that have been proven to have effects on the activity of sex hormones via its interaction with the androgen receptors (Kjeldsen et al., 2013). A recent study also demonstrated that Mancozeb can significantly alter the ion channel functions and thereby induce cellular toxicity in the nervous system (Li et al., 2013). Mancozeb was found to significantly reduce the sperm counts and sperm motility in rats (Girish and Reddy, 2018). However, no evidence is available on the effects of Mancozeb or any other dithiocarbamate on sperm functions. Human and animals are at risk of being acute exposure to Mancozeb via Food and feed. Therefore, the present study was undertaken to assess the effect of acute exposure of Mancozeb on spermatozoa motility, and functions using freshly ejaculated bovine semen from fertility proven bulls reared in an artificial insemination centre in Sri Lanka. 


\section{METHODOLOGY}

\section{Animals and Experimental Location}

For the current study, seven fertile Jersey bulls at the age of 3-4 years, reared under standard conditions at the Central Artificial Insemination Centre, Kundasale, Sri Lanka were selected. The semen samples were collected and evaluated on the same day at the laboratory at Central Artificial Insemination Centre in Kundasale, Sri Lanka. The sperm motility ( $>90 \%$ motile), and concentrations of the samples were analysed before being selected for further experimentation.

\section{Exposure of Spermatozoa to Mancozeb}

The standard artificial vagina-based collection method was used to collect semen for routine processing and the same researcher performed all the assessments of semen in order to avoid any subjective errors. The sperm samples were kept in a modified Tyrode's solution $(300 \mathrm{mOsm} / \mathrm{L} \mathrm{g} / \mathrm{L}$, $8.18 \mathrm{~g} / \mathrm{L} \mathrm{NaCl}, 0.24 \mathrm{~g} / \mathrm{L} \mathrm{KCl}, 0.04 \mathrm{~g} / \mathrm{L} \mathrm{Na}_{2} \mathrm{HPO}_{4}, 2.18$ $\mathrm{g} / \mathrm{L} \quad \mathrm{NaHCO}_{3}, 0.08 \mathrm{~g} / \mathrm{L} \quad \mathrm{MgCl}_{2} .6 \mathrm{H}_{2} \mathrm{O}, 0.31 \mathrm{~g} / \mathrm{L}$ $\mathrm{CaCl}_{2} .2 \mathrm{H}_{2} \mathrm{O}, 0.94 \mathrm{~g} / \mathrm{L}$ glucose, $2.48 \mathrm{~g} / \mathrm{L}$ HEPES and distilled water) to keep the sperms alive as explained by Farrell et al. (1996)., (The samples were diluted to a working concentration of $25 \times 10^{6}$ sperm $/ \mathrm{mL}$ for the use in further analysis. The temperature of the semen samples was maintained at $37^{\circ} \mathrm{C}$ using an open water bath incubator.

Equal amounts (4 mL) of diluted spermatozoa were exposed to $0.1,1$ and $10 \mu \mathrm{g} / \mu \mathrm{L}$ concentrations of analytical grade Mancozeb (Sigma-Aldrich) dissolved in DMSO (SigmaAldrich) with a control (DMSO only) and was incubated at $37{ }^{\circ} \mathrm{C}$ for $0,1,2,4$ and $6 \mathrm{hr}$ time durations. Each treatment and time duration were triplicated for the semen of the seven bulls. After the incubation, samples from each treatment at different time-points were assessed for total sperm motility using Computer Assisted Spermatozoa Analysis (CASA) as described below.

In the first set of experiments, only the total motility was assessed to decide the concentration and time duration of incubation for the subsequent experiments. Based on the initial concentration and time dependent analysis, the subsequent experiments were carried out with $1 \mu \mathrm{g} / \mu \mathrm{L}$ analytical grade Mancozeb and matching concentration of commercially used Mancozeb $(80 \% \mathrm{w} / \mathrm{w})$ for $2 \mathrm{hr}$ of the incubation period to mimic the acute phase of exposure. Semen collected from each individual animal was subjected to the experimental conditions without pooling.

\section{Computer Assisted Spermatozoa Analysis (CASA)}

The CASA was performed according to the manufacturer's guidelines (Hamilton-throne integrated visual optic system, Animal version 12.3h, build 001 for Windows, Beverly, Mass, USA), and as described by Farrell et al. (1996). After each treatment and time duration, $20 \mu \mathrm{L}$ of each sample was loaded into a clean 20 - $\mu$ m-deep chamber (SC20-01-04-B, Leja, GN Nieuw-Vennep, Netherlands), covered with a cover slip, and was placed on a stage warmer fixed to a negative phase contrast trinocular microscope (Carl Zeiss Microscopes, Germany) at $37^{\circ} \mathrm{C}$. A minimum of 500 sperms from at least five different fields were analyzed for each sample, and at least three slides from each replicate were subjected to CASA to obtain the mean values. The percentage of motile sperms and progressive motility were recorded. The kinetic parameters of sperms; straight line velocity/progressive velocity (VSL $\mu \mathrm{m} / \mathrm{sec}$ ), curvilinear velocity (VCL $\mu \mathrm{m} / \mathrm{sec}$ ), average path velocity (VAP $\mu \mathrm{m} / \mathrm{sec}$ ), amplitude of lateral head displacement (ALH $\mu \mathrm{m})$, beat cross frequency (BCF beats/sec), linearity percentage (VSL/VCL), straightness percentage (VSL/VAP) and elongation (head width to length ratio \%), were calculated automatically using CASA. The CASA recorded 150 frames per second (fps), and sperms having more than 120 frames were used for further analysis.

\section{Acrosome Integrity Assay}

Acrosome integrity test was performed to determine live and dead sperms with or without acrosome (Serafini et al., 2014). The sperm samples were diluted with $0.9 \% \mathrm{NaCl}$ and mixed with $0.27 \%$ trypan blue prior to cell counting. All slides were air-dried at room temperature and was fixed with a fixative solution (86 $\mathrm{ml} 1 \mathrm{~N} \mathrm{HCL}$ and 14 $\mathrm{ml}$ of $37 \%$ formaldehyde with $0.2 \mathrm{~g}$ Neutral Red). The sperm samples were carefully washed with distilled water and stained in $7.5 \%(\mathrm{v} / \mathrm{v})$ Giemsa solution for 18 - $20 \mathrm{hr}$. After staining, the sperm smears were rinsed with distilled water and tap water. The slides were air-dried at room temperature to fix. Finally, microscopic evaluations of the spermatozoa were carried out using a light microscope (Nikon, Japan) with a 100 $\times$ objective with oil immersion. The sperms were separated into two categories based on the staining: acrosome-intact live (AIL) and acrosomeintact dead (AID). 


\section{Acrosine Proteolytic Activity (APA) Assay}

A modified gelatin digestion assay (Arabi and Mohammadpour, 2006) was performed to determine the ability of bull spermatozoa to undergo acrosomal exocytosis/acrosin activity. One hundred $\mu \mathrm{L}$ of $7.5 \%$ gelatin suspension was smeared evenly on pre-cooled (at $4{ }^{\circ} \mathrm{C}$ ) microscopic slides. The slides were kept horizontally until dry and fixed for two minutes in $0.05 \%$ (v/v) glutaraldehyde before washing thoroughly in phosphate buffer solution (PBS) and distilled water. The slides were kept overnight in a moist chamber at $4{ }^{\circ} \mathrm{C}$. Fifty microliters of diluted sperm suspension were placed on one end of the slide and was smeared with a cover glass. The slides were placed horizontally to dry and was incubated in a moist chamber at $38{ }^{\circ} \mathrm{C}$, in a $5 \% \mathrm{CO}_{2}$ incubator for $24 \mathrm{hr}$. After incubation, the slides were observed using a phase-contrast microscope (Nikon, Japan) with a 400× magnification. A clear halo around the sperm head indicated acrosome proteolytic activity (APA). At least 200 sperms from each slide were assessed and the percentage of sperms showing a halo was recorded.

\section{Statistical Analysis}

The data were analysed using one-way analysis of variation (ANOVA), followed by mean separation (Mean \pm SD) using SAS, version 9.1 (SAS Institute for advanced analytics, USA).

\section{RESULTS}

\section{Concentration and Time-dependent Effects of Mancozeb on the Motility of Spermatozoa}

The total motility of the sperm was significantly decreased after two hours of incubation with of Mancozeb $1 \mu \mathrm{g} / \mathrm{mL}(76.0 \pm 1.8 \%)$ and $10 \mu \mathrm{g} / \mathrm{mL}$

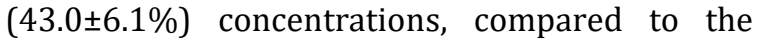
control (85.3 $\pm 2.4 \%$ ) (Fig. 1). After four hours of incubation, Mancozeb concentrations of $0.1,1$ and $10 \mu \mathrm{g} / \mathrm{mL}$ significantly suppressed sperm motility resulting $76.3 \pm 3.6 \%, 62.3 \pm 5.6 \%$ and $26 \pm 5.9 \%$ mobility levels, respectively. At six hours of incubation, sperm in $10 \mu \mathrm{g} / \mathrm{mL}$ Mancozeb concentration were completely immotile, and all other treatment groups and the control, showed a significant $(p<0.05)$ decrease in total sperm motility (Fig. 1). Since significant change in motility was observed after two hours of incubation with 1 $\mu \mathrm{g} / \mathrm{ml}$ Mancozeb (76\%), this concentration was used in subsequent experiments.

\section{Effects of Mancozeb on Sperm Motility}

Prior to treatments, the CASA values (total motility, progressive motility, APV, CLV, ALH, BCF, SLV, straightness, linearity and elongation) of the untreated semen samples among different bulls were not significantly different. Incubation with Mancozeb $(1 \mu \mathrm{g} / \mathrm{ml})$ for two hours significantly $(p<0.05)$ changed the CASA parameters. In these experiments, commercially available Mancozeb $(80 \% \mathrm{w} / \mathrm{w})$ was compared with analytical grade pure Mancozeb standard treatments. Both the pure and commercial Mancozeb treatments significantly $(\mathrm{p}<0.05)$ reduced the total motility, progressive motility, APV, CLV, SLV and ALH of spermatozoa compared to the non-treated control (Fig. 2). The BCF and elongation were significantly $(p<0.05)$ decreased when the sperm were treated with commercial grade Mancozeb and not with analytical grade pure Mancozeb (Fig. 2). Both pure and commercial Mancozeb did not significantly $(p \leq 0.05)$ change the straightness and linearity of the motility of sperm at a two-hour incubation period.

\section{Effect of Mancozeb on Acrosome Integrity}

Acrosome integrity of the exposed sperms after incubating in $1 \mu \mathrm{g} / \mathrm{ml}$ pure and commercial Mancozeb for two hours were determined using micrographs stained with trypan blue/gisema stains. The percentage of acrosome intact live spermatozoa was significantly $(\mathrm{p} \leq 0.05)$ lower in both pure and commercial Mancozeb groups $(67.03 \pm 1.71 \%$ and $65.83 \pm 2.94 \%)$ than in the control (85.37 $\pm 5.31 \%$ ) (Fig. 3). Moreover, the percentage of acrosome intact dead sperm was also significantly ( $\mathrm{p} \leq 0.05$ ) higher in the Mancozebtreated groups than in the control.

\section{Effect of Mancozeb on Acrosine Proteolytic Functions}

The standard in vitro gelatin digestion test revealed that both pure and the commercial Mancozeb preparations have significantly $(p<0.001)$ increased the percentage of spermatozoa with impaired acrosine activity (Fig. 4). 


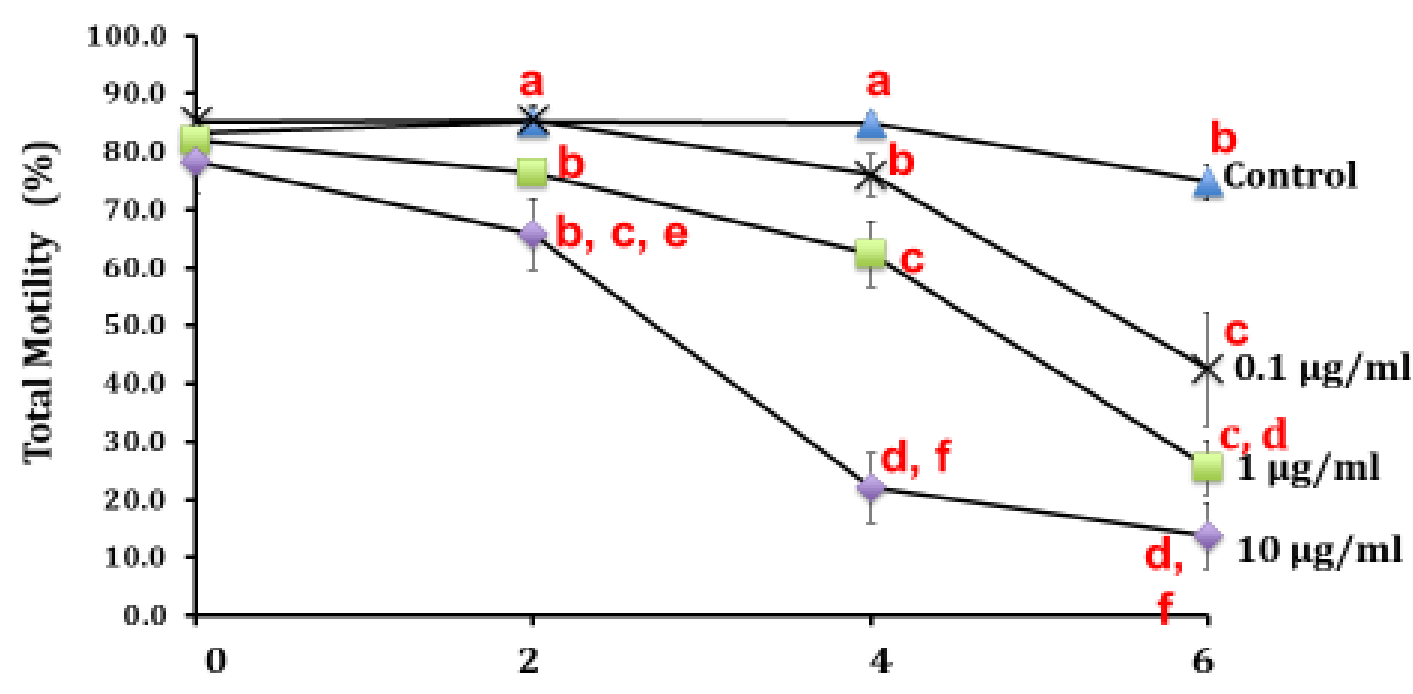

Mancozeb incubation time (hr)

Figure 1: Concentration and Time Dependent Effects of Mancozeb on Bovine Sperm Motility. Note: $a, b, c, d, e$, and $f$ denote significant different from each other at $p<0.05$.
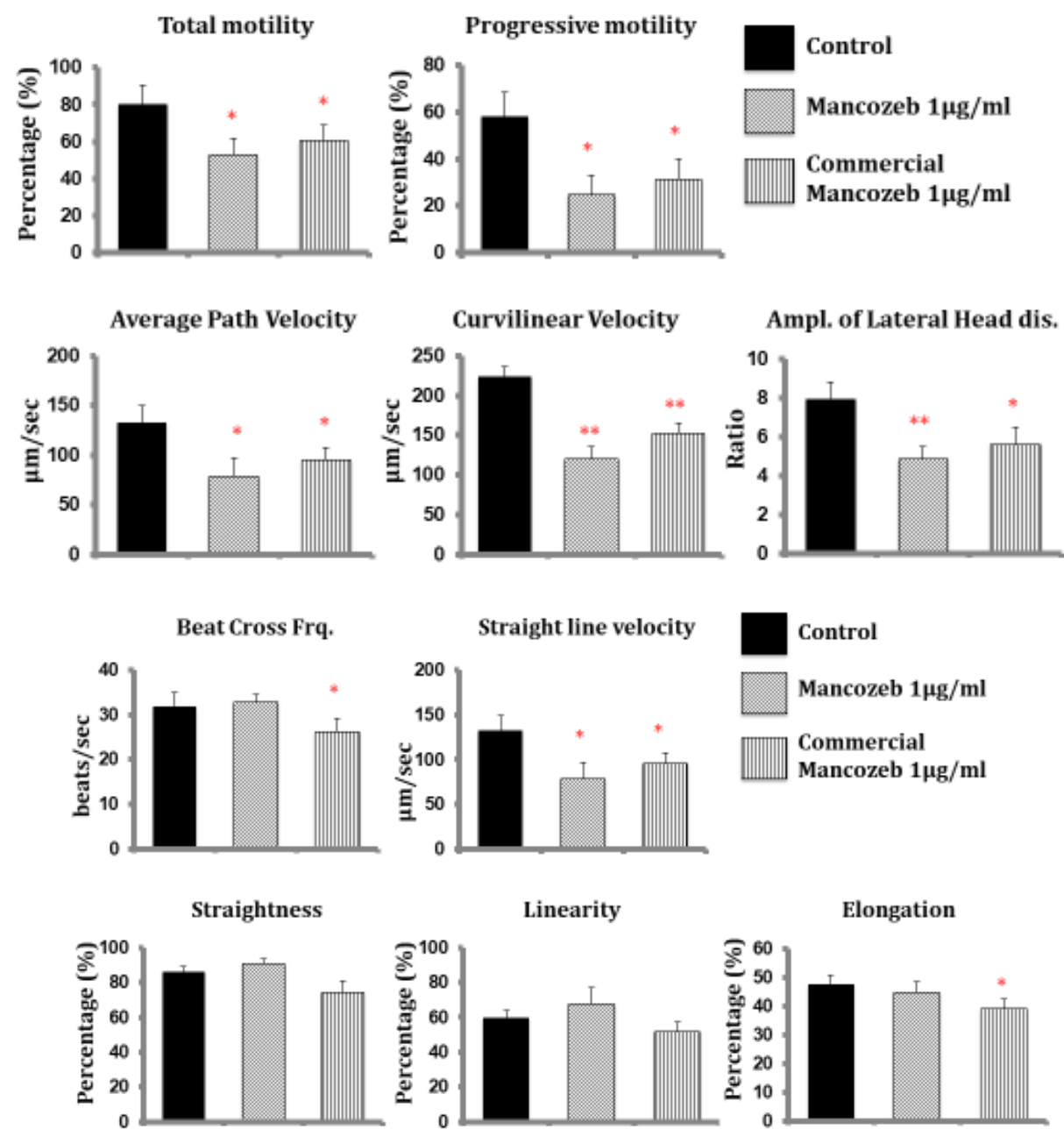

Figure 2: Effect of Mancozeb $(1 \mu \mathrm{g} / \mathrm{ml})$ on various motility parameters of the Bovine Sperm Motility Parameter at $2 \mathrm{hrs}$ treatment period. 
A

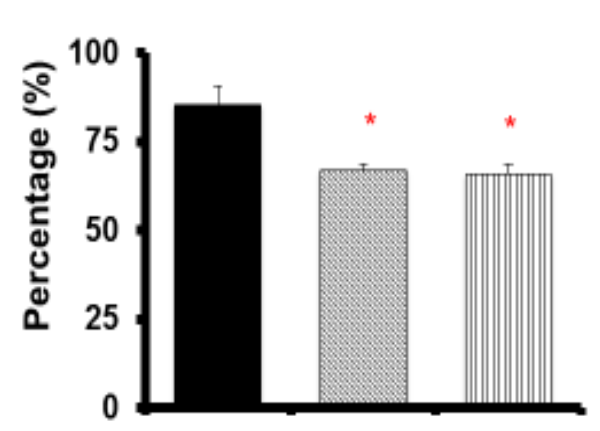

B

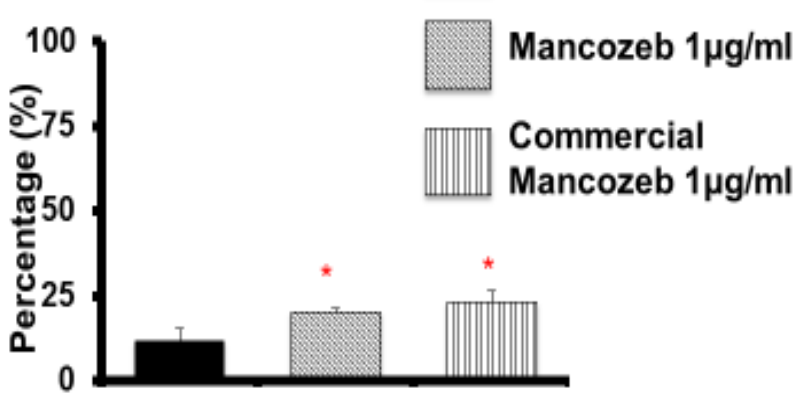

Figure 3: Effect of the Mancozeb on Sperm Acrosome Integrity Using Trypan Blue/Geisma Staining. (A) The percentage of sperm with intact acrosome after treatment with $1 \mu \mathrm{g} / \mathrm{ml}$ Mancozeb for $2 \mathrm{hrs}$. (B). The percentage of acrosome-intact dead spermatozoa after treatment with $1 \mu \mathrm{g} / \mathrm{ml}$ Mancozeb for 2 hrs. * denotes significantly difference from the control at $\mathbf{p}<0.05$.

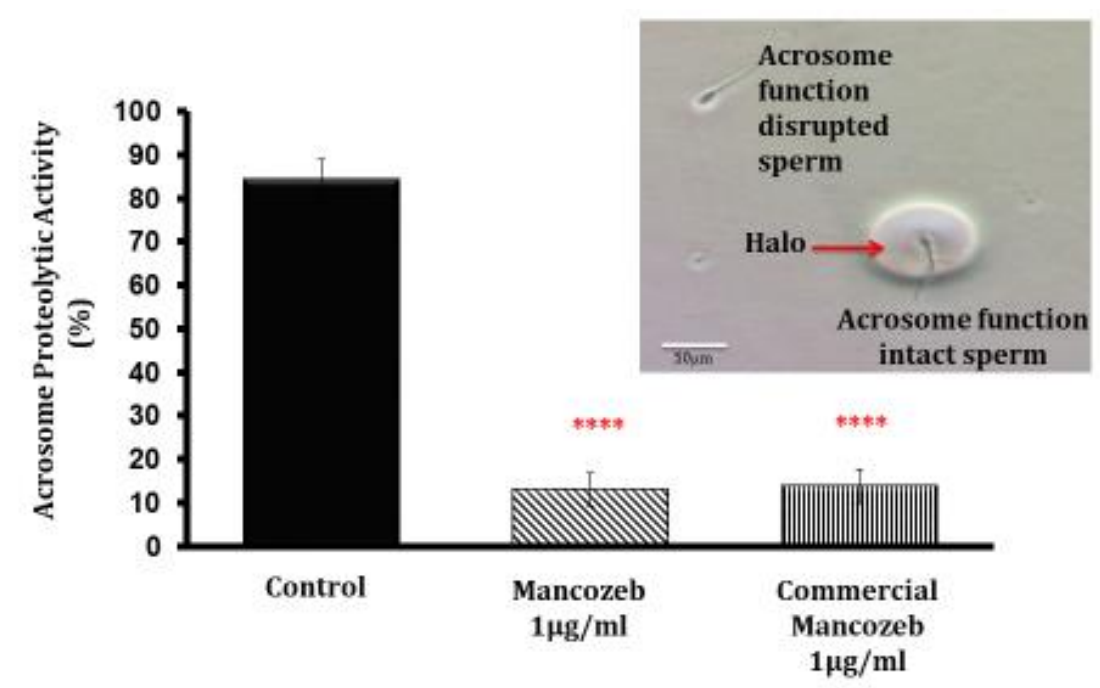

Figure 4: Effect of Mancozeb on Acrosine Proteolytic Activity Measured by Gelatin Digestion Assay. $* * * *$ denotes significant difference in halo bearing sperm when compared to the untreated control at $\mathbf{p}<0.001$.

\section{DISCUSSION}

In the current study, the effect of Mancozeb on bovine sperm motility and functions was investigated in an in vitro setup, and it was found that pure and commercially available Mancozeb at 1 and $10 \mu \mathrm{g} / \mathrm{mL}$ concentrations significantly affected sperm motility within two hours. In vitro treatment with Mancozeb reduced acrosome integrity and proteolytic activity of acrosome, suggesting an impairment of fertilization capacity of bovine sperm both in vitro and in vivo.
The present study mainly focused on the acute effect of Mancozeb on sperm functions but not the spermatogenesis process, as certain pesticides have the ability to retain in the body for a certain extent (Kamarianos et al., 2003). Results from mice model studies have demonstrated that an oral dose of Mancozeb at $800 \mathrm{mg} / \mathrm{kg}$ can suppress the testicular functions including spermatogenesis (Ksheerasagar and Kaliwal, 2003). The current study used ejaculated semen samples from fertile bulls to study the effect of Mancozeb on sperm functions. However, whether Mancozeb could disrupt the blood-testis barrier in bulls remains largely unknown. In the present study, we have 
selected the doses of Mancozeb based on the previous human exposure data (Hoffman and Hardej, 2012; Lesmes-Fabian \& Binder, 2013; Hoffman, et al., 2016), and used doses that are far below the reported concentration in the circulatory system after acute exposure. Moreover, modified Tyrode's solution without swim up procedure, was used to dilute the semen, since the experiments were carried out to evaluate the short-term effect of Mancozeb by CASA to avoid any interference from the presence of any inert matter in the semen diluent (Farrell et al., 1996).

In the current study, CASA was used to investigate the full spectrum of the effect of Mancozeb on different sperm motility parameters since previous studies on similar line too have investigated the full spectrum of the motility parameters with CASA (Farrell et al., 1996; Kanno et al., 2017). The significant reduction of total motility was observed after two hours of incubation at the concentrations of 1 and $10 \mu \mathrm{g} / \mathrm{ml}$. Thus, $1 \mu \mathrm{g} / \mathrm{ml}$ concentration of Mancozeb with a two-hour incubation was selected for the subsequent experimental conditions to evaluate the acute effects of Mancozeb on ejaculated spermatozoa. No acute effects were revealed during the short exposure times of $0.5 \mathrm{hr}$ and $1 \mathrm{hr}$ (data not shown) while the highest concentration $(10 \mu \mathrm{g} / \mathrm{ml})$ showed the maximum effects on sperm motility at all the exposure times tested. Osmotic shock due to high concentration also could have played a vital role leading to acute effects in the $2 \mathrm{hr}$ exposure period.

Pure and commercial Mancozeb preparations with matching concentration of active ingredients were used in the subsequent studies. Both pure and commercial preparations significantly altered sperm parameters including total motility, progressive motility, APV, CLV and ALH. These findings on Mancozeb tally well with the similar effects reported on the sperm parameters in rats and rabbits for pesticides; permethrin, cypermethrin and 3-phenoxybenzoic acid (Yuan et al., 2010) fenvalerate and cypermethrin (Song et al., 2008), and bendicarb (Krockova et al., 2012). In the present study, only commercial Mancozeb significantly reduced the BCF and elongation (head width to length ratio) of the spermatozoa, indicating that other substances may be present in the commercial Mancozeb. Straightness and linearity of the spermatozoa were not affected by both preparations of Mancozeb indicating that the active ingredient in Mancozeb does not cause any physical change to the spermatozoa upon exposure. Since various surfactants are added during the formulation of commercial preparation, to enhance the potency of Mancozeb. Similar observations in relations to some herbicides and pesticides has been reported by Chen et al. (2018) and Janssens and Stoks, (2017). Among sperm motility parameters, VCL and BCF indicate the viability of spermatozoa, and VSL, STR, LIN and VAP indicate the progression of spermatozoa whereas LIN and STR indicate the swimming patterns of sperms. All these are important parameters for successful oocyte penetration (Duty et al., 2004; Holden et al., 2017; Kasimanickam et al., 2007). As CASA parameters have a direct correlation with the fertilization capacity of spermatozoa (Kasimanickam et al., 2007; Martins et al., 2009; Matas et al., 2010; Sariozkan et al., 2014; Sariozkan et al., 2015; Sapanidou et al., 2016; Holden et al., 2017), results from the current findings suggest that acute Mancozeb exposure can significantly reduce the acrosome activity that may lead to reduce the fertilization capacity of spermatozoa. In addition, Mancozeb was found to regulate ion channels in other cell types (Li et al., 2013), and ion channel activities are associated with sperm motility (Candenas et al., 2018; Chauhan et al., 2018). In fact, many pesticides are found to alter mitochondrial functions on energy production, resulting in a decrease in cell motility, eventually leading to cell death. This could partly explain why the sperm progression parameters were affected more than the sperm viability when treated with Mancozeb (Betancourt, Resendiz, \& Fierro, 2006). Moreover, sperm motility could be affected via other cellular processes including activation of the dynein ATPase, increase of internal $\mathrm{pH}$, the cAMP kinase activity and the calcium/calmodulindependent adenylyl cyclase activity (Yuan et al., 2010). Future investigation should be focused on the role of Mancozeb in reducing sperm motility through regulation of ion channel activity, as well as the presence of other possible chemical/contaminants that impair sperm motility.

Trypan blue/Geisma staining which was used to evaluate the membrane integrity of the acrosome showed that both Mancozeb types significantly ( $p$ $<0.05$ ) reduced the membrane integrity, while keeping acrosome intact. Membrane integrity is a clear indicator of the viability and hence fertilizing ability of the spermatozoa (Serafini et al., 2014). Therefore, collapse of membrane integrity may further contribute to the reduction of the ability of fertilization of the treated spermatozoa. We further observed that Mancozeb could significantly destabilize the sperm acrosome and its proteolytic functions, which acts as an enzymatic drill during sperm penetration of the oocyte. The proteolytic enzymes activity inside the acrosome, which was assessed by gelatin digestion, plays an important role in the sperm-oocyte penetration process, and 
serve as a direct indicator of the fertilization ability of the sperm (Thundathil et al., 2001). Osmotic tolerance is now considered as another parameter (Yeste et al., 2010) to evaluate the fertilization ability of a given sample of ejaculated sperm. Compared to the effect of Mancozeb on acrosome integrity, the acrosine proteolytic activity has severely been disrupted by the Mancozeb treatment. This possibly indicates that, other than disturbing the acrosome membrane, Mancozeb may have some other mode of action to reduce the proteolytic activities. However, it is noteworthy that the sperm is known to have very little transcription and other cellular signaling activates compared to somatic cells. Interestingly, Mancozeb was found to act through steroids receptors in the cells (Ghisari et al., 2015) and sperm is also known to express functional androgen receptors (Aquila et al., 2007; Zuccarello et al., 2009). Therefore, understanding the functions of steroids receptors on the spermatozoa may help to realise how Mancozeb modulate acrosome functions through steroid receptors. In addition, a recent study suggested that Mancozeb can act as a possible genotoxic compound inducing DNA damage in oocytes and other cell types (Goldoni et al., 2014; Marques et al., 2016; Paz-Trejo \& Gomez-Arroyo, 2017) Integrity of the sperm DNA is very important for the proper gene expression and regulation during the transcription, and transfer the genetic material to the next generation after fertilization. Thus, it is worthwhile to examine the effects of Mancozeb on sperm DNA integrity to obtain a better understanding the impact of Mancozeb on sperm function both in vitro and in vivo conditions.

\section{REFERENCES}

Adewoyin, M., Ibrahim, M., Roszaman, R., Isa, M.L.M., Alewi, N.A.M., Rafa, A.A.A. and Anuar, M.N.N. (2017). Male Infertility: The Effect of Natural Antioxidants and Phytocompounds on Seminal Oxidative Stress. [Review]. Diseases, 5(1). doi: 10.3390/diseases5010009

Albrecht, C., Caniggia, I., Clifton, V., Gohner, C., Harris, L., Hemmings, D. and Salomon, C. (2016). IFPA meeting 2015 workshop report IV: Nanomedicine applications and exosome biology, xenobiotics and endocrine disruptors and pregnancy, and lipid mediators and placental function.

Aquila, S., Middea, E., Catalano, S., Marsico, S., Lanzino, M., Casaburi, I. and Ando, S. (2007). Human sperm express a functional androgen

\section{CONCLUSIONS}

Mancozeb can significantly impair sperm motility, reduce the acrosome integrity and the acrosome proteolytic activities which may associated with low fertilization ability of sperm. The presence of other chemical/contaminant in the commercial Mancozeb may exert additional risks to normal sperm functions, and thus warrants further investigation.

\section{ACKNOWLEDGEMENTS}

The authors greatly acknowledge the technical support rendered by the staff of the Central Artificial Insemination Centre, Kunadasala, Sri Lanka and partial funding supports from CRCG of The University of Hong Kong, IFS-Sweden (grant B5367-1), NSF-Sri Lanka (Grant RG/2014/HS/06) and NRC-Sri Lanka (Grant 13-059). Authors also wish to acknowledge Dr. Dimanthi Jayathilake, Department of Agriculture Biology, Faculty of Agriculture, University of Peradeniya for critically commenting on the manuscript.

\section{Declaration/Competing Interest}

All the authors have read and agreed to the content of the manuscript and there are no competing interests among the authors.

receptor: effects on PI3K/AKT pathway. Human Reproduction, 22(10), 2594-2605.

Arabi, M. and Mohammadpour, A.A. (2006). Adverse effects of cadmium on bull spermatozoa. Veterinary Research and Communication. 30(8), 943-951.

Baligar, P.N. and Kaliwal, B.B. (2001). Induction of gonadal toxicity to female rats after chronic exposure to Mancozeb. Industrial Health, 39(3), 235-243.

Betancourt, M., Resendiz, A. and Fierro, E.C. (2006). Effect of two insecticides and two herbicides on the porcine sperm motility patterns using computer-assisted semen analysis (CASA) in vitro. Reproductive Toxicology, 22(3), 508-512.

Candenas, L., Pinto, F.M., Cejudo-Roman, A., Gonzalez-Ravina, C., Fernandez-Sanchez, M., 
Perez-Hernandez, N. and Subiran, N. (2018). Veratridine-sensitive $\mathrm{Na}(+)$ channels regulate human sperm fertilization capacity. Life Sciences, 196, 48-55.

Cecconi, S., Paro, R., Rossi, G. and Macchiarelli, G. (2007). The effects of the endocrine disruptors dithiocarbamates on the mammalian ovary with particular regard to mancozeb. Current Pharmaceutical Design, 13(29), 2989-3004.

Chauhan, D.S., Swain, D.K., Shah, N., Yadav, H.P., Sharma, A., Yadav, B. and Garg, S.K. (2018). Modulation of voltage-gated sodium channels induces capacitation in bull spermatozoa through phosphorylation of tyrosine containing proteins. Theriogenology, 108, 207-216.

Chen, J., Fine, J.D. and Mullin, C.A. (2018). Are organosilicon surfactants safe for bees or humans? Science of the Total Environment, 612, 415-421.

Chiu, Y.H., Afeiche, M.C., Gaskins, A.J., Williams, P.L., Petrozza, J.C., Tanrikut, C. and Chavarro, J.E. (2015). Fruit and vegetable intake and their pesticide residues in relation to semen quality among men from a fertility clinic. Human Reproduction, 30(6), 1342-1351.

Colosio, C., Fustinoni, S., Birindelli, S., Bonomi, I., De Paschale, G., Mammone, T. and Maroni, M. (2002). Ethylenethiourea in urine as an indicator of exposure to mancozeb in vineyard workers. Toxicology Letters, 134(1-3), 133140.

Colosio, C., Visentin, S., Birindelli, S., Campo, L., Fustinoni, S., Mariani, F. and Maroni, M. (2006). Reference values for ethylenethiourea in urine in Northern Italy: results of a pilot study. Toxicology Letters, 162(2-3), 153-157.

Crowe, M.A., Hostens, M. and Opsomer, G. (2018). Reproductive management in dairy cows - the future. [Review]. Irish Veterinary Journal, 71, 1. doi: 10.1186/s13620-017-0112-y

de Angelis, C., Galdiero, M., Pivonello, C., Salzano, C., Gianfrilli, D., Piscitelli, P. and Pivonello, R. (2017). The environment and male reproduction: The effect of cadmium exposure on reproductive function and its implication in fertility. [Review]. Reproductive Toxicology, 73, 105-127.

Den Hond, E., Tournaye, H., De Sutter, P., Ombelet, W., Baeyens, W., Covaci, A and D'Hooghe, T. (2015). Human exposure to endocrine disrupting chemicals and fertility: A casecontrol study in male subfertility patients. Environment International, 84, 154-160.

Duty, S.M., Calafat, A.M., Silva, M.J., Brock, J.W., Ryan, L., Chen, Z. and Hauser, R. (2004). The relationship between environmental exposure to phthalates and computer-aided sperm analysis motion parameters. Journal of Andrology, 25(2), 293-302.

Ewence, A., Brescia, S., Johnson, I. and Rumsby, P.C. (2015). An approach to the identification and regulation of endocrine disrupting pesticides. Food and Chemical Toxicology, 78, 214-220.

Farrell, P.B., Foote, R.H., McArdle, M.M., TrouernTrend, V.L. and Tardif, A.L. (1996). Media and dilution procedures tested to minimize handling effects on human, rabbit, and bull sperm for computer-assisted sperm analysis (CASA). Journal of Andrology, 17 (3), 293-300.

Ghisari, M., Long, M., Tabbo, A. and BonefeldJorgensen, E.C. (2015). Effects of currently used pesticides and their mixtures on the function of thyroid hormone and aryl hydrocarbon receptor in cell culture. Toxicology and Applied Pharmacology, 284(3), 292-303.

Girish, B.P. and Reddy, P.S. (2018). Forskolin ameliorates mancozeb-induced testicular and epididymal toxicity in Wistar rats by reducing oxidative toxicity and by stimulating steroidogenesis. Journal of Biochemical and Molecular Toxicology, 32(2).

Giulivo, M., Lopez de Alda, M., Capri, E. and Barcelo, D. (2016). Human exposure to endocrine disrupting compounds: Their role in reproductive systems, metabolic syndrome and breast cancer. Environmental Research, 151, 251-264.

Goldoni, A., Klauck, C.R., Da Silva, S.T., Da Silva, M.D., Ardenghi, P.G. and Da Silva, L.B. (2014). DNA damage in Wistar rats exposed to dithiocarbamate pesticide Mancozeb. Folia Biologica (Praha), 60(4), 202-204.

Hoffman, L. and Hardej, D. (2012). Ethylene bisdithiocarbamate pesticides cause cytotoxicity in transformed and normal human colon cells. Environmental Toxicology and Pharmacology, 34(2), 556-573.

Hoffman, L., Trombetta, L. and Hardej, D. (2016). Ethylene bisdithiocarbamate pesticides Maneb and Mancozeb cause metal overload in human 
colon cells. Environmental Toxicology and Pharmacology, 41, 78-88.

Holden, S.A., Fernandez-Fuertes, B., Murphy, C., Whelan, H., O'Gorman, A., Brennan, L. and Fair, S. (2017). Relationship between in vitro sperm functional assessments, seminal plasma composition, and field fertility after AI with either non-sorted or sex-sorted bull semen. Theriogenology, 87, 221-228.

Iorio, R., Castellucci, A., Rossi, G., Cinque, B., Cifone, M.G., Macchiarelli, G. and Cecconi, S. (2015). Mancozeb affects mitochondrial activity, redox status and ATP production in mouse granulosa cells. Toxicology In Vitro, 30(1 Pt B), 438-445.

Iorio, R., Castellucci, A., Ventriglia, G., Teoli, F., Cellini, V., Macchiarelli, G. and Cecconi, S. (2014). Ovarian toxicity: from environmental exposure to chemotherapy. [Review]. Current Pharmaceutical Design, 20(34), 5388-5397.

Janssens, L. and Stoks, R. (2017). Stronger effects of Roundup than its active ingredient glyphosate in damselfly larvae. Aquatic Toxicology, 193, 210-216

Kamarianos, A., Karamanlis, X., Theodosiadou, E., Goulas, P. and Smokovitis, A. (2003). The presence of environmental pollutants in the semen of farm animals (bull, ram, goat, and boar). Reproductive Toxicology, 17(4), 439445.

Kasimanickam, R., Kasimanickam, V., Thatcher, C.D., Nebel, R.L. and Cassell, B.G. (2007). Relationships among lipid peroxidation, glutathione peroxidase, superoxide dismutase, sperm parameters, and competitive index in dairy bulls. Theriogenology, 67(5), 1004-1012.

Kjeldsen, L.S., Ghisari, M. and Bonefeld-Jorgensen, E.C. (2013). Currently used pesticides and their mixtures affect the function of sex hormone receptors and aromatase enzyme activity. Toxicology and Applied Pharmacology, 272(2), 453-464.

Krockova, J., Massanyi, P., Toman, R., Danko, J. and Roychoudhury, S. (2012). In vivo and in vitro effect of bendiocarb on rabbit testicular structure and spermatozoa motility. Journal of Environmental Science and Health, Part A, 47(9), 1301-1311.

Ksheerasagar, R.L. and Kaliwal, B.B. (2003). Temporal effects of mancozeb on testes, accessory reproductive organs and biochemical constituents in albino mice. Environmental Toxicology and Pharmacology, 15(1), 9-17.

Lesmes-Fabian, C. and Binder, C.R. (2013). Pesticide flow analysis to assess human exposure in greenhouse flower production in Colombia. International Journal of Environmental Research and Public Health, 10(4), 1168-1185.

Li, P., Zhu, J., Kong, Q., Jiang, B., Wan, X., Yue, J. and Gao, Z. (2013). The ethylene bisdithiocarbamate fungicide Mancozeb activates voltage-gated KCNQ2 potassium channel. Toxicology Letters, 219(3), 211-217.

Liu, Y. and Ding, Z. (2017). Obesity, a serious etiologic factor for male subfertility in modern society. [Review]. Reproduction, 154(4), R123R131.

Marques, A., Rego, A., Guilherme, S., Gaivao, I., Santos, M.A. and Pacheco, M. (2016). Evidences of DNA and chromosomal damage induced by the Mancozeb-based fungicide Mancozan((R)) in fish (Anguilla anguilla L.). Pesticide Biochemistry and Physiology, 133, 52-58.

Martins, CF., Driessen, K., Costa, P.M., CarvalhoNeto, J.O., de Sousa, R. V., Rumpf, R. and Dode, M.N. (2009). Recovery, cryopreservation and fertilization potential of bovine spermatozoa obtained from epididymides stored at $5{ }^{\circ} \mathrm{C}$ by different periods of time. Animal Reproduction Science, 116(1-2), 50-57.

Matas, C., Sansegundo, M., Ruiz, S., Garcia-Vazquez, F.A., Gadea, J., Romar, R. and Coy, P. (2010). Sperm treatment affects capacitation parameters and penetration ability of ejaculated and epididymal boar spermatozoa. Theriogenology, 74(8), 1327-1340.

Melodie, V.B. and Christine, W. (2018). Fertility and infertility: Definition and epidemiology. [Review]. Clinical Biochemistry.

Mendonca, C.R., Arruda, J.T., Noll, M., Campoli, P.M.O. and Amaral, W.N.D. (2017). Sexual dysfunction in infertile women: A systematic review and meta-analysis. [Review]. European Journal of Obstetrics and Gynecology and Reproductive Biology, 215, 153-163.

Nicolopoulou-Stamati, P., Maipas, S., Kotampasi, C., Stamatis, P. and Hens, L. (2016). Chemical Pesticides and Human Health: The urgent need for a new concept in agriculture. [Review]. Frontiers in Public Health, 4, 148. 
Niederberger, C. (2016). Fruit and vegetable intake and their pesticide residues in relation to semen quality among men from a fertility clinic. Journal of Urology, 195(2), 448.

Olsen, J., Zhu, J.L. and Ramlau-Hansen, C.H. (2011). Has fertility declined in recent decades? Acta Obstetricia et Gynecologica Scandinavica, 90(2), 129-135.

Paro, R., Tiboni, G.M., Buccione, R., Rossi, G., Cellini, V., Canipari, R. and Cecconi, S. (2012). The fungicide Mancozeb induces toxic effects on mammalian granulosa cells. Toxicology and Applied Pharmacology, 260(2), 155-161.

Paz-Trejo, C. and Gomez-Arroyo, S. (2017). Genotoxic evaluation of common commercial pesticides in human peripheral blood lymphocytes. Toxicology and Industrial Health, 33(12), 938-945.

Rao, M.V., Sundar, R.S. and Chawla, S.L. (2005). Reproductive toxicity of a fungicide combination (Metalaxyl + Mancozeb) in adult male rats. Journal of Cell and Tissue Research, 5(1), 299-302.

Rossi, G., Buccione, R., Baldassarre, M., Macchiarelli, G., Palmerini, M.G. and Cecconi, S. (2006a). Mancozeb exposure in vivo impairs mouse oocyte fertilizability. Reproductive Toxicology, 21(2), 216-219.

Rossi, G., Palmerini, M.G., Macchiarelli, G., Buccione, R. and Cecconi, S. (2006b). Mancozeb adversely affects meiotic spindle organization and fertilization in mouse oocytes. Reproductive Toxicology, 22(1), 51-55.

Runkle, J., Flocks, J., Economos, J. and Dunlop, A.L. (2017). A systematic review of Mancozeb as a reproductive and developmental hazard. [Review]. Environment International, 99, 2942.

Sapanidou, V., Taitzoglou, I., Tsakmakidis, I., Kourtzelis, I., Fletouris, D., Theodoridis, A. and Tsantarliotou, M. (2016). Protective effect of crocetin on bovine spermatozoa against oxidative stress during in vitro fertilization. Andrology, 4(6), 1138-1149.

Sariozkan, S., Bucak, M.N., Tuncer, P.B., Buyukleblebici, S. and Canturk, F. (2014). Influence of various antioxidants added to TCM199 on post-thaw bovine sperm parameters, DNA integrity and fertilizing ability. Cryobiology, 68(1), 129-133.
Sariozkan, S., Bucak, M.N., Tuncer, P.B., Buyukleblebici, S., Eken, A. and Akay, C. (2015). Influence of fetuin and hyaluronan on the postthaw quality and fertilizing ability of Holstein bull semen. Cryobiology, 71(1), 119-124.

Sengupta, P. and Banerjee, R. (2014). Environmental toxins: alarming impacts of pesticides on male fertility. [Review]. Human and Experimental Toxicology, 33(10), 10171039.

Serafini, R., Longobardi, V., Spadetta, M., Neri, D., Ariota, B., Gasparrini, B. and Di Palo, R. (2014). Trypan blue/giemsa staining to assess sperm membrane integrity in salernitano stallions and its relationship to pregnancy rates. Reproduction in Domestic Animals, 49(1), 4147.

Sifakis, S., Androutsopoulos, V.P., Tsatsakis, A.M. and Spandidos, D.A. (2017). Human exposure to endocrine disrupting chemicals: effects on the male and female reproductive systems. [Review]. Environmental Toxicology and Pharmacology, 51, 56-70.

Skinner, M.K. (2016). Endocrine disruptors in 2015: Epigenetic transgenerational inheritance. [Review]. Nature Reviews Endocrinology, 12(2), 68-70.

Song, L., Wang, Y.B., Sun, H., Yuan, C., Hong, X., Qu, J.H. and Wang, X.R. (2008). Effects of fenvalerate and cypermethrin on rat sperm motility patterns in vitro as measured by computerassisted sperm analysis. Journal of Toxicology and Environmental Health, Part A, 71(5), 325332.

Sweeney, M.F., Hasan, N., Soto, A.M. and Sonnenschein, C. (2015). Environmental endocrine disruptors: Effects on the human male reproductive system. Reviews in Endocrine and Metabolic Disorders, 16(4), 341357.

Szabo, R., Budai, P., Fejes, S., Varnagy, L. and Keseru, M. (2003). Embryonic toxicity of a mancozeb containing fungicide formulation and $\mathrm{Cu}$ sulphate in pheasant after individual or combined administration. Communications in Agricultural and Applied Biological Sciences, 68(4 Pt B), 803-806.

Thundathil, J., Palomino, J., Barth, A., Mapletoft, R. and Barros, C. (2001). Fertilizing characteristics of bovine sperm with flattened or indented 
acrosomes. Animal Reproduction Science, 67 (34), 231-243.

Tournaye, H., Krausz, C. and Oates, R.D. (2016). Novel concepts in the aetiology of male reproductive impairment. [Review]. Lancet Diabetes and Endocrinology.

Yeste, M., Briz, M., Pinart, E., Sancho, S., Bussalleu, E. and Bonet, S. (2010). The osmotic tolerance of boar spermatozoa and its usefulness as sperm quality parameter. Animal Reproduction Science, 119(3-4), 265-274.

Yoldemir, T. and Oral, E. (2012). Has fertility declined in recent decades? [Review]. Current
Opinion in Obstetrics and Gynecology, 24(3), 119-126.

Yuan, C., Wang, C., Gao, S.Q., Kong, T.T., Chen, L., Li, X.F. and Wang, Y.B. (2010). Effects of permethrin, cypermethrin and 3phenoxybenzoic acid on rat sperm motility in vitro evaluated with computer-assisted sperm analysis. Toxicology In Vitro, 24(2), 382-386.

Zuccarello, D., Garolla, A., Ferlin, A., Menegazzo, M., De Toni, L., Carraro, M. and Foresta, C. (2009). Androgen receptor is expressed in both $\mathrm{X}$ - and Y-carrier human spermatozoa. Fertility and Sterility, 91(1), 193-200 